\title{
БАНКОВСКАЯ
} АЕЯТЕАЬНОСТЬ

\section{РожАественская Т.Э.}

\section{ПУБАИЧНОЕ БАНКОВСКОЕ ПРАВО: ПРЕАMET, МЕТОА, СИСТЕМА}

\begin{abstract}
Аннотация. В статье рассматриваются сформировавщиеся подходы к банковскому праву. Автор обосновывает суждение о выделении в банковском праве двух сфер правового регулирования: публиного банковского права и частного банковского права. Предметом исследования являются общественные отношения, относящиеся к публичному банковскому праву. Автором определены предмет публичного банковского права и методы правового регулирования, присущие публиному банковскому праву. Определен круг об-щественных отночений, регулируемых нормами публиного банковского права. Определена система публиного банковского права. В процессе работы применялся сравнительно-правовой метод исследования, а также анализ, синтез, позволившие сформумировать следующие выводы Автором сделан вывод, что специфика банковской деятельности, роль кредитных институтов в современной экономике, особенности их отночений скредиторами, и прежде всего вкладчиками, породили необходимость значительного публичного вмешательства в деятельность кредитных институтов. Отмечено, что публично-правовые нормы составляют основу современного регулирования банковской деятельности.
\end{abstract}

Кнючевые слова: банковское право, публчное банковское право, предмет, метод, система банковского права, банковская деятельность, правовое регулирование, частное банковское право, общественные отночения, правовые нормы.

Review. The article reviews the currently existing approaches towards banking law. The author gives proof of the reasonability of demarcating between two spheres of public control in banking law - public banking law and private banking law. The subject analyzed in the article is social relations that have to do with public banking law. The author determines the subject of public banking law and the methods of legal regulations specific for public banking law. He also demarcates the sphere of social relations that are regulated by the norms of public banking law and determines the system of public banking law. 
The author uses the method of comparing laws, as well as methods of analysis and synthesis, which allows him to come to the following conclusions: the specifics of banking activity, the role of credit institutions in modern economy and several peculiarities of their relations with creditors - first of all, with depositors - bring to life the necessity of considerable public interference in the activity of credit institutions. He also notes that public legal norms form the basis of up-to-date regulations of banking activities.

Keywords: private banking law, legal regulation, banking, system of banking law, method, subject, public banking law, banking law, social relations, legal norms.

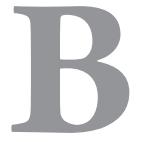

научной митературе традиционно преАметом банковского права признаются общественные отношения, возникающие в процессе осуществления банковской деятельности, т.е.предусмотренных законом банковских операций банками и иными кредитными организациями с целью извлечения прибыли, а также (в случаях, преАусмотренных законом) 一 иными субъектами.

В настоящее время существует несколько точек зрения на место банковского права в системе права:

- банковское право как институт (подотрасль) финансового права;

- банковское право как самостоятельная отрасль права;

- банковское право как комплексная отрасль права;

- банковское право как отрасль законодательства.

Так, по мнению М.М. Агаркова, банковское право - это «совокупность юриАических норм, регулирующих организацию и деятельность банков», а преАметом банковского права является сам банк и присущие ему слеАующие функции: собирание чужих среАств; оказание креАита; содействие платежному обороту ${ }^{[1, c .6-7]}$.

А.А. Тедеев отмечает, что предметом банковского права являются общественные отношения, которые возникают в сфере банковской Аеятельности и формируются в процессе функционирования банковской системы РФ ${ }^{[12, c .13]}$.

С точки зрения О.М. ОАейник в преАмете банковского права выделяются: 1) отношения, возникающие в процессе созАания банковской системы; 2) правоотношения с участием банков по поводу Авижения финансовых инструментов как среАств обращения, сбережения и как товара ${ }^{[11, c .33]}$.

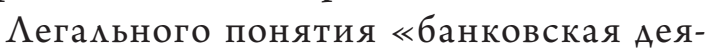
тельность» в российском законодате ьстве нет, однако определение банковской Аеятельности содержится в ст. 12 Банковского кодекса Республики Беларусь, согласно которой «банковская Аеятельность - совокупность осуществияемых банками и небанковскими кредитно-финансовыми организациями банковских операций, направленных на извмечение прибыли» ${ }^{[4]}$.

Как следствие, банковское право рассматривается как совокупность правовых норм, регулирующихотАельные гражАанские (учреАительные, обязательственные) отношения, участниками которых явмяются кредитные организации. Так, В. Белов пишет, что «банковское законодательство (и банковское право в объективном смысле) - совокупность норм, регламентирующих банковскую Аеятельность, т.е. порядок совершения перечисленных выше банковских сАе бок $_{\text {[Аоговоры банков- }}$ ского счета, вкмада (Аепозита) и кредита и некоторые Аругие - авторы], особенности правового положения самих банков, ихучредителей и работников, вызванные именно специфическим («банковским») характером Аеятельности» ${ }^{[5, c .17]}$.ПреАставители этого подхода часто не скмонны рассматривать банковское право как самостоятельную правовую общность. А. Г. ЕфимоваутвержАает, что «банковское право не явцяется ни самостоятельной отраслью права, ни подотраслью права...», потомучто «те общественные отношения, которые регулируются «банковским правом», нельзя признать настолько своеобразными, чтобы они могми составить 
преАмет особой отрасли права». Также и методправового регулирования в «банковском праве» не явмяется особым методом, а преАстав яет собой смешение метоАов, присущих аАминистративному и гражАанскому праву. Таким образом, «банковское право» - всего $\Lambda$ ишь УАобный термин, который «прочно вошем в профессионацьный язык практических работников» ${ }^{[9, c .4-5] . ~ И ~ А е и ̆ с т в и т е л ь н о, ~}$ если рассматривать банковское право как совокупность норм, регулирующих отАельные гражАанско-правовые отношения, возникающие в процессе осуществления банковской Аеятельности, то оно не может претендовать на что-то Аругое, кроме как быть УАобным и привычным термином.

Иной подхоА, берущий траАицию еще в советском правоведении, рассматривает банковское право как подотрасль финансового права (О.Н. Горбунова ${ }^{[7, c .15]}$ и Ар.). СлеАствием Аанного поАхода явмяется «Погружение» регулирования банковской Аеятельности в сферу публичных отношений, т.к. финансовое право традиционно и бесспорно относится к сфере публичного права.

ПоАхоА к банковскому праву только как праву публичному, как подотрасли (институту) финансового права оправдан в случае, когАа банковская система явмяется эмементом государственного (аАминистративного) механизма и играет роль перераспределения Аенежных ресурсов на основе государственного плана. Именно такой быма банковская система в рамках социалистического хозяйства. Не случайно, еще в 1952 году И. С. Гуревич рассматривац банковское право (советское банковское право) как подотрасль финансового права, то есть «совокупность родственных институтов финансового права, регулирующих общественные отношения, возникающие в процессе осуществления банковских операций, направменныхна обеспечение хозяйственной Аеяте ьности организаций и обскуживание гражАан» $[8, c .16,26]$.

РяА авторов ${ }^{[2]}$ развивают идею банковского права как самостоятемьной отрасли права, т.н. «комплексной» отрасли права. По мнению указанных авторов, «банковское право как отрасль российского права преАстав яет собой совокупность норм, регулирующих отношения, возникающие в процессе построения, функционирования и развития банковской системы Российской Фелерации, в том числе в процессе регулирования банковской деятельности со стороны Банка России и Аругих органов государственной в асти, а также союзов и ассоциаций кредитных организаций». В банковском праве содержатся нормы и используются методы правового регукирования размичных отраслей права, в связи с чем оно является комплексной отраслью права ${ }^{[2, c .20]}$. Несмотря на то, что ранее действительно высказывалась идея комплексной отрасли права, сегоАня эта идея не находит своего подтвержАения в теории права. В самом Аеле, если «метод определяется преАметом ... и поэтому преАстав яяет собой юриАическое выра-

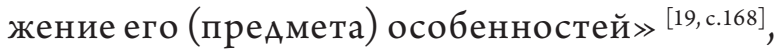
отсутствие своеобразия в методе правового регулирования, по меньшей мере, свидетельствует о том, что преАмет правовой общности, которая рассматривается в указанной работе, как отрасль, неоднороден в правовом смысле слова, не может считаться настолько еАиным, чтобы рассматриваться как относительно самостоятельный виА общественных отношений.

Наконец, в науке была сформулирован поАхоА к банковскому правуне как к отрасли (подотрасли, институту) права, а как к комплексной отрасли законодате ьства. Указанная точка зрения нашла отражение в работах

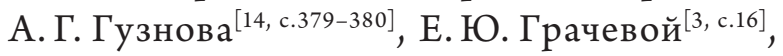
Т.Э. РожАественской ${ }^{[15, c .11-12 ; 16, c .14-15]}$, Е. Г. Хоменко ${ }^{[3, \text { c.16] }}$ и Ар.

В соответствии с Аанным подходом банковское право преАставляет собой комплексную отрасль законодательства, включающую в себя как правовые акты, содержащие нормы пубцичного права, связанные с публичным интересом, сотношениями власти и поА- 
чинения, так и правовые акты, содержащие нормы частного права, основанные на автономии участников. Как отмечает Е. Ю. Грачева, «банковское право явмяется отраслью законодатемьства, вкцючающей комп екс норм публично-правового и частноправового характера, направленных на регулирование отношений, возникающих по повоАу и (ими) в процессе осуществцения банковской Аеятемьности» ${ }^{[3, c .16]}$.

В отмичие от отраслей права, отрасли законодательства, «регулируя определенные сферы госуАарственной жизни, вылемяются только по преАмету и не имеют еАиного метода. Кроме того, предмет отрасли законодатемьства вкмючает в себя размичные отношения, в связи с чем и отрасль законодатемьства не явмяется столь оАнородной, как отрасль права ${ }^{[13, \text { c. 377] }}$.

Нормы, входящие в состав банковского права, могут относиться к конституционному праву (например, вопросы статуса центрахьного банка), финансовому праву (например, отношения, связанные с осуществмением Аенежно-креАитной помитики ими банковского надзора), гражАанскому праву (кредит, вкмаА, счет, расчеты).

ИсхоАЯ из изложенного, вПолне обоснованно выдемять в банковском праве Аве сферы правового регукирования:

1) публичное банковское право;

2) частное банковское право.

В этой связи существенным явмяется понимание отмичий публичного права от права частного.

Размичение публичного права и права частного - Аостижение римской науки права. Первое «(относится) к положению римского госуаарства», второе - «к пользе отАемьных миц». Кроме этого, умьпиановского разАеления частного и публичного права по обособцению общего (общественного) и $\Lambda$ ичного (частного) интереса, известно еще нескомько попыток такого разАеления.

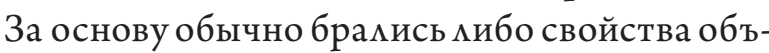
ективного права, нормативной стороны пра- ва, $и$ ио свойства юриАических отношений, субъективного права.

В советское время Аеление права на частное и публичное бымо отвергнуто в связи с тем, что всякое право бымо признано пубАичным.

Пубкичное право в современности это:

3) право, которое направмено на защиту публичного интереса - интереса государства, общества, народа, неопределенного круга $\Lambda$ иц;

4) право, основным принципом которого явмяется суборАинация, иерархия.

Понятие и содержание пубмичного интереса исследовалось в работах многих ученых: Ю.А. Тихомирова, А. В. Кряжкова, М.И. Васимьевой, А.Я. Курбатова и Ар.

Как отмечаетЮ.А.Тихомиров, понятие «публичный интерес явмяется родовым, вкАючающим в себя более конкретные, видовые понятия. Признание, выражение и обеспечение разных общественных интересов по субъектам создают прочный конституционный фунаамент, гарантируют выражение интересов в разных сферах жизни общества, отсюда вытекает правообразующая роль Аанной категории во всех отраслях пубцичного права» [17, с.60]. «Таким образом, публичный интерес есть признанный государством и обеспеченный правом интерес социа ьной общности, УАовметворение которого служит условием и гарантией ее существования и развития» $[17, \mathrm{c.3}]$.

Публичному праву присущ императивный метоА правового регулирования, хотя также в ряде случаев возможно применение рекоменаатемьного метода.

Исходя от отмеченных выше особенностей современных критериев публичного права, к преАмету правового регукирования пубмичного банковского права следует отнести следующие группы общественных отношений:

1) статус центрахьного банка (а в странах, гАе орган банковского наАзора существует 
отАельно от центрального банка - статус органа банковского регулирования и банковского наАзора), его компетенцию, систему управления;

2) отношения, связанные с осуществлением задач денежно-кредитной политики;

3) отношения, связанные с осуществлением заАач банковского наАзора, вкмючая:

- отношения, возникающие в процессе государственной регистрации креАитных организаций и мицензировании банковской деятельности;

- отношения, связанные с применением к кредитным организациям мер воздействия со стороны Банка России;

4) отношения, связанные с системой страхования (гарантирования) вкцадов в банках;

5) отношения, связанные с противодействием отмыванию доходов, покученных преступным путем, и финансированию терроризма;

6) отношения, связанные с функционированием национацьной платежной системы.

Правовые нормы, регумирующие указанные группы отношений, Аифференцируются и группируются в правовые институты, взаимосвязь и взаимодействие которых и образуют систему публичного банковского права.

В послеанее время оАной из основных цемей финансовых вмастей и, в частности, центральных банков признается Аостижение и подАержание финансовой устойчивости. Этому служат как задачи, выполняемые в рамках денежно-креАитной политики, так и в сфере банковского наАзора.

На пубцичное банковское право оказывает значительное влияние международное право. Регулирование современных финансовых рынков в принципе не может замыкаться в национацьных границах, так как отсутствие Аолжного регулирования в оАном сегменте (географическом или функциональном) финансового рынка может привести к кризису, способному вызвать «эффект домино» на межаународном уровне. Вопросы финансовой
Устойчивости являются основным направлением Аеятельности таких объединений и органов как, к примеру, Группа 20 (G20), МВФ и группа Всемирного банка, Совет по финансовой стабимьности.

Межаународные финансовые кризисы привели к созАанию специализированных межАународных организаций, нацеменных на выработку стандартов банковского наАзора и банковской деятельности во всем мире. К ним относится прежАе всего Базельский комитет по банковскому наАзору, который был учрежден центральными банками т.н. «группы-10» (G-10) в 1974 году после банкротства одного из крупных немецких межАународных банков («BankhausHerrstatt”), которое оказало самое негативное виияние на международные расчеты и банковский рынок. Целью Комитета является распространение наикучшей наАзорной практики, обеспечение кооперации между органами банковского наАзора разАичных государств, созАание Условий Аля обмена наАзорной информацией как межАу органами банковского наАзора, так и межАу органами наАзора на иных финансовых рынках (прежде всего - рынке ценных бумаг и страховом рынке ${ }^{[22, p .24]}$. Базельский комитет по банковскому надзору не обладает вмастными полномочиями и не может рассматриваться как наАнационацьный орган. Формы его работы - рекоменаации, основные направления и т.А., то есть тот массив актов, который с некоторых пор покучим название «softlaw» [23, p. 33]. Вместе с тем, эти рекоменАации, наА которыми работают совместно специалистынадзорных органов размичных стран, не могут не учитываться как в повсеАневной практике национальных органов банковского наАзора, так и при формировании национацьного банковского законодательства. Важнейшим документом Базельского комитета по банковскому наАзору явцяется акт, имеющий название «Основные принципы эффективного банковского наАзора» (Cor ePrinciplesforEffectiveBankingSupervision $)^{[c .16]}$. 
Таким образом, можно выделить основные отличия публичного банковского права от частного банковского права.

Частное банковское право регулирует Аеятельность креАитных организаций осуществление ими банковских операций (в том числе расчетов) и иных саелок, их

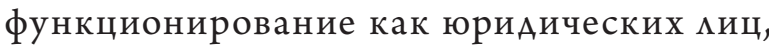
обладающих специфическими правомочиями, определяет их отношения с кмиентами и, прежАе всего, с кредиторами. Банковский наАзор, Аенежно-кредитная политика, система страхования вкмадов и иные сферы публично-правового регулирования занимают применительно к частному банковскому праву вторичное место и как бы обслуживают основную группу правоотношений, так или иначе завязанную на понятие банковской Аеятельности.

Публичное банковское право в своем серАцевине регулирует отношения, связанные с организацией денежного обращения, с использованием денежных среАств в качества основного инструмента стимукирования социально-экономического Развития, ПоААержания социальной стабимьности. Эмиссия Аенежных средств, проведение ее способами, обеспечивающими независимость эмиссионного центра (центрального банка) от правительства, осуществление денежно-кредитной политики, нацеменной на обеспечение финансовой устойчивости,- все эти вопросы возникают как преАмет публичного интереca, интереса как государства, так и общества.

Кредитные организации в этой связи явАяются оАним из инструментов ПровеАения Аенежно-креАитной политики. Поэтому необходимо обеспечение их устойчивости как с помощью экономических методов, свойственных денежно-кредитной сфере, так и методами банковского наАзора. Немаловажным также явмяется вопрос о подАержании системы, которая позволяла бы предупрежАать вовлеченность кредитных организаций в осуществление сомнительных операций, связанных с отмыванием преступных Аоходов и финансированием терроризма. Наконец, подАержание необходимого уровня Аоверия к национальным денежным средствам и инструментам и, как слеАствие, уровня Аоверия к банковской системе требует созАания системы страхования вкмаАов и эффективной системы предупреждения банкротства банков, а также некоторых иных финансовых институтов (например, страховых организаций, негосударственных пенсионных фондов, инфраструктурных финансовых организаций).

Аемение банковского права на публичное и частное с присущими каждому из них своих методов правового регулирования необходимо прежАе всего Аля Аифференциации «гкубины» правового регулирования государством отдельных аспектов банковской Аеятельности. Вопросы банковской Аеятельности, относящиеся к частно-правовому регулированию, преАполагают использование Аиспозитивного метода правового регуиирования, основывающегося на равенстве сторон и договоре. Публичное банковское право, базирующееся на публичном интересе, преАполагает императивный метод правового регулирования, опирающийся на неравенство сторон и императивные преАписания, закрепленные в нормативно-правовых актах, несоблюдение которых ведет к применению к поднадзорным субъектам мер воздействия со стороны регулятора - Банка России.

Пубцично-правовые нормы составцяют основу современного регулирования банковской деятельности.

Специфика банковской деятельности, роль креаитных институтов в современной экономике, особенности их отношений с креАиторами и, прежАе всего, вкиаАчиками, породими необходимость значительного публичного вмешательства в Аеятельность креАитных институтов. Не случайно в настоящее время практически во всех странах функционируют органы банковского наАзора, основной целью которых явмяется поААержание стабильности и развития банковских систем, защита интересов креАиторов и вклаАчиков. 


\section{БИБАИОГРАФИЯ}

1. Агарков М.М. Основы банковского права: курс мекций. Учение о ценных бумагах: научное исследование. 3-е изА. М., 2005.

2. Банковское право Российской ФеАерации. Общая часть: Учебник / Под общ. реА. Б. Н. Топорнина.- М., Юрист, 1999.

3. Банковское право Российской Федерации: учеб.пособие/отв. реА. Е. Ю. Грачева.- М.: Норма, 2008.

4. Банковский кодекс Республики Беларусь // СПС «Гарант».

5. Белов В.А. Банковское право России: теория, законодательство, практика: ЮриАические очерки.- М.: Учебно-консультационный центр «ЮрИнфоР», 2000.

6. Братко А.Г. Запреты в советском праве. Саратов. 1979.

7. Горбунова О.Н. Выделять банковское право в отАельную отрасль права пока рано // ЮриАический мир. 1998. № 8.

8. Гуревич И.С. Очерки советского банковского права.- -., 1952.

9. Ефимова $\Lambda$. Г. Банковское право/ Учебное и практическое пособие. - М.: ИзА-во «БЕК», 1994.

10. Ефимова А. Г. Банковские слелки: право и практика. Монография. М.: НИМП, 2001.

11. Олейник О.М. Основы банковского права: курскекций / О. М. Окейник. М.: Юристъ, 1997.

12. Тедеев А.А. Банковское право: учеб. / А. А. Тедеев. М.: Эксмо, 2005.

13. Теория государства и права. Курс кекций / Под реА. Н.И. Матузова и А. В. Малько. М.: Юристь, 1997.

14. Правоведение: Учебник Аля вузов/под реА. С.Н. Бабурина. - М.: Из-Аательство «НОР$\mathrm{MA} \gg, 2003$.

15. РожАественская Т.Э. Банковское право: учеб. пособие.— М.:, РПА МЮ РФ, 2006.

16. РожАественская Т.Э. Банковское право: учеб. пособие.- М.: ИзА. Аом Гос. ун-та - Высшей школы экономики, 2010.

17. Тихомиров Ю.А. Публичное право. Учебник.-М: ИзА-во БЕК, 1995.

18. Симановский А.Ю. Базельские принципы эффективного банковско-го наАзора и их реамизация в России // Аеньги и креАит. 2001.31.03.

19. Спиридонов $\Lambda$.И.. Теория государства и права: Курс мекций.- СПб: «Санкт-петербургская ВШМ МВА РФ, 1995.— С. 168.

20. Финансовое право: учеб.- 3-е изА., перераб. и Аоп. ; отв. реА. Е. Ю. Грачева, Г.П. Толстопятенко.- М.: «Проспект», 2010.

21. Финансовое право: учебник/отв. реА. Н.И. Химичева. - 4-е изА., пе-рераб. и Аоп.- М.: Норма, 2008.

22. Халфина Р. О. Общее учение о правоотношении. М., 1974; Ткаченко Ю. Г. Методологические вопросы теории правоотношений. М., 1980.

23. History of the Basle Committeeandits Membership / Compendium of documents produced by the Basle Committee on Banking Supervision/-Bank for International Settlement, Basle, Switzerland.

24. Giovanioli M.. A new architecture for the Global Financial Market: Le-gal aspects of international standard setting // In: International monetary law: Is-sues for the New Millenium / Ed. by M. Givanioli. - Oxford University Press Inc., NY., 2000.

\section{REFERENCES (TRANSLITERATED)}

1. Agarkov M.M. Osnovy bankovskogo prava: kurs lektsii. Uchenie o tsennykh bumagakh: nauchnoe issledovanie. 3-e izd. M., 2005. 
2. Bankovskoe pravo Rossiiskoi Federatsii. Obshchaya chast': Uchebnik / Pod obshch. red. B. N. Topornina. - M., Yurist, 1999.

3. Bankovskoe pravo Rossiiskoi Federatsii: ucheb.posobie/otv. red. E. Yu. Gracheva. - M.: Norma, 2008.

4. Bankovskii kodeks Respubliki Belarus' // SPS 'Garant'.

5. Belov V.A. Bankovskoe pravo Rossii: teoriya, zakonodatel'stvo, praktika: Yuridicheskie ocherki.M.: Uchebno-konsul'tatsionnyi tsentr 'YurInfoR', 2000.

6. Bratko A. G. Zaprety v sovetskom prave. Saratov. 1979.

7. Gorbunova O.N. Vydelyat' bankovskoe pravo v otdel'nuyu otrasl' prava poka rano // Yuridicheskii mir. 1998. № 8.

8. Gurevich I. S. Ocherki sovetskogo bankovskogo prava._L L., 1952.

9. Efimova L.G. Bankovskoe pravo/ Uchebnoe i prakticheskoe posobie.-M.: Izd-vo 'BEK', 1994.

10. Efimova L. G. Bankovskie sdelki: pravo i praktika. Monografiya. M.: NIMP, 2001.

11. Oleinik O.M. Osnovy bankovskogo prava: kurs lektsii / O. M. Oleinik. M.: Yurist”, 1997.

12. Tedeev A.A. Bankovskoe pravo: ucheb. / A. A. Tedeev. M.: Eksmo, 2005.

13. Teoriya gosudarstva i prava. Kurs lektsii / Pod red. N. I. Matuzova i A. V. Mal'ko. M.: Yurist”, 1997.

14. Pravovedenie: Uchebnik dlya vuzov/pod red. S. N. Baburina.-M.: Iz-datel'stvo 'NORMA', 2003.

15. Rozhdestvenskaya T.E. Bankovskoe pravo: ucheb. posobie.-M.:, RPA MYu RF, 2006.

16. Rozhdestvenskaya T.E. Bankovskoe pravo: ucheb. posobie. - M.: Izd. Dom Gos. un-ta — Vysshei shkoly ekonomiki, 2010.

17. Tikhomirov Yu.A. Publichnoe pravo. Uchebnik. - M: Izd-vo BEK, 1995.

18. Simanovskii A. Yu. Bazel'skie printsipy effektivnogo bankovsko-go nadzora i ikh realizatsiya v Rossii // Den'gi i kredit.2001.31.03.

19. Spiridonov L.I.. Teoriya gosudarstva i prava: Kurs lektsii. — SPb: 'Sankt-peterburgskaya VShM MVD RF, 1995.- S. 168.

20. Finansovoe pravo: ucheb.-3-eizd., pererab.i dop.; otv. red.E. Yu. Gracheva, G. P. Tolstopyatenko.M.: 'Prospekt', 2010.

21. Finansovoe pravo: uchebnik/otv. red. N.I. Khimicheva.—4-e izd., pe-rerab.i dop.—M.: Norma, 2008.

22. Khalfina R. O. Obshchee uchenie o pravootnoshenii. M., 1974; Tkachenko Yu.G. Metodologicheskie voprosy teorii pravootnoshenii. M., 1980.

23. History of the Basle Committeeandits Membership / Compendium of documents produced by the Basle Committee on Banking Supervision/-Bank for International Settlement, Basle, Switzerland.

24. Giovanioli M.. A new architecture for the Global Financial Market: Le-gal aspects of international standard setting // In: International monetary law: Is-sues for the New Millenium / Ed. by M. Givanioli. - Oxford University Press Inc., NY., 2000. 